\title{
O estômago equino: agressão e mecanismos de defesa da mucosa
}

\author{
The equine stomach: aggression and defense mechanisms of the mucosal
}

\author{
José Ramón Martinez Aranzales ${ }^{\mathrm{I}}$ Geraldo Eleno Silveira Alves ${ }^{\mathrm{II}}$
}

\section{- REVISÃo BIBLIOGRÁFICA -}

\section{RESUMO}

\begin{abstract}
O estômago dos equinos tem particularidades anatômicas e fisiológicas que facilitam a ocorrência de alterações inflamatórias, degenerativas e obstrutivas, além de sensibilidade frente a mudanças de condições externas. A superfície da mucosa gástrica é coberta por epitélio tanto escamoso como glandular, com mecanismos de proteção deficiente e eficiente, respectivamente. Na rotina clínica, são frequentes prevalências e incidências aumentadas de lesões derivadas de processos locais ou sistêmicos.
\end{abstract}

Palavras-chave: equino, epitélio glandular, ácido clorídrico, citoproteção.

\section{ABSTRACT}

The equine stomach has anatomical and physiological peculiarities that facilitate the production of inflammatory, degenerative and obstructive disorders, besides being sensitive to external factors changes. The gastric surface is covered by squamous epithelium and glandular epithelium with poor and efficient mechanisms of protection respectively. In clinical practice, increased prevalence and incidence are common due to local and remote processes.

Key words: horse, glandular epithelium, hydrochloric acid, cytoprotection.

\section{INTRODUÇÃO}

O estômago dos equinos constitui um compartimento sacular do sistema digestório de importância na fisiologia geral do trato gastrintestinal, que pode ser alterado por condições localizadas antes e após esse órgão, além das disfunções primárias derivadas de suas próprias estruturas anatômicas. Por conseguinte, a sanidade gástrica depende de um ciclo mastigatório equilibrado e da reciprocidade funcional normal com os segmentos intestinais. Além disso, apresenta sensibilidade a fatores externos, como o manejo e o ambiente.

Particularidades do estômago nos equinos e a combinação de fatores predisponentes facilitam a ocorrência de gastrites e outras gastropatias caracterizadas por processos degenerativos ou regenerativos. Em sua maioria, as afecções gástricas ocorrem sem manifestações clínicas, que dependem da intensidade e localização das alterações na superfície gástrica ou no restante do trato gastrintestinal, como em quadros de desconforto abdominal.

Prevalências e incidências aumentadas de lesões gástricas têm sido descritas após a disponibilidade de equipamentos auxiliares ao diagnóstico, que permitem evidenciar fatores predisponentes de lesão e correlacionar com outras disfunções orgânicas, possibilitando dimensionar os efeitos negativos, gerados para populações de equinos e para a indústria equestre em geral.

IEscuela de Medicina Veterinaria, Facultad de Ciencias Agrarias, Grupo de Investigación Centauro, Universidad de Antioquia (UdeA), Ciudadela Robledo, Carrera 75, n. 65-87, Medellín, Antioquia, Colombia. E-mail: jrramonmvz@yahoo.com. Autor para correspondência.

"IDepartamento de Clínica e Cirurgia Veterinárias, Escola de Veterinária, Universidade Federal de Minas Gerais (UFMG), Belo Horizonte, MG, Brasil. 
A importância no estudo do estômago vem sendo enfatizada recentemente, devido à elevada casuística de gastropatias e à associação com outras entidades clínicas envolvidas, como as alterações dentárias, da motilidade gastrintestinal e do comportamento na espécie equina. Este artigo aborda aspectos anatômicos, fisiopatológicos e mecanismos de defesa e de agressão na mucosa gástrica, visando colaborar para a abordagem de quadros clínicos que comprometem de alguma maneira o estômago do paciente equino.

Aspectos anatômicos e fisiológicos do estômago O estômago do cavalo tem uma capacidade que varia entre 7,5 a 15 litros, sendo pequeno em relação aos compartimentos subsequentes do trato digestório, já que só representa entre 8 e $10 \%$ de seu volume (AL JASSIN \& ANDREWS, 2009). Anatomicamente, o estômago possui curvaturas maior e menor, cuja superfície interna é integrada por quatro regiões: cárdica, fúndica, corpo e pilórica. A parede gástrica é constituída pela serosa, três camadas musculares, submucosa e mucosa. A mucosa possui duas áreas que são denominadas pavimentosa ou não glandular e a secretora ou glandular, pelo que se considera um estômago unicavitário composto (KÖNIG et al., 2004). $\mathrm{Na}$ interface dessas áreas, está o margo plicatus, área em que há prevalência aumentada de lesões ulcerativas (ANDREWS, 2005).

A mucosa glandular do estômago representa os 2/3 da superfície gástrica interna, em que há produção de ácido clorídrico e pepsinogênio. Também é onde há efetivos mecanismos protetores, como a produção de muco, bicarbonato e rápida re-epiteliação da mucosa. Contudo, é a área em que ocorrem aproximadamente $20 \%$ das úlceras (VIDELA \& ANDREWS, 2009, BUCHANAN \& ANDREWS, 2003). Aárea não glandular, aproximadamente $1 / 3$, tem epitélio escamoso estratificado sem auto-proteção eficiente, o que leva à predisposição para a ocorrência de $80 \%$ das lesões por causticação ácida (MURRAY, 2009). Do ponto de vista histológico, existem diferenças estruturais e funcionais entre os epitélios das duas áreas da mucosa. $\mathrm{O}$ desenvolvimento destas duas superfícies começa ao final da gestação e período neonatal. Nas duas primeiras semanas após do nascimento, o epitélio pavimentoso entra em hiperplasia, em resposta à exposição ácida, e o epitélio glandular se diferencia totalmente (MURRAY, 1999).

A área glandular possui em sua extensão uma variedade de glândulas, como as cárdicas e pilóricas produtoras de muco gástrico; as glândulas próprias ou fúndicas, com células acessórias produtoras de muco; células parietais secretoras do ácido clorídrico; células principais secretoras de pepsinogênio; células D secretoras de somatostatina; células $\mathrm{G}$ produtoras de gastrina; e células semelhantes à enterocromafim, secretoras de histamina e serotonina (MERRIT, 1999), sendo essas últimas mais presentes na região pilórica.

O maior volume do fluido do estômago origina-se pela secreção ácida contínua com ou sem presença de alimento, variando de 10 a 30 litros dia $^{-1}$. Além do ácido clorídrico, o conteúdo gástrico contém saliva, ácidos graxos voláteis (AGV) e secreção intestinal por refluxo duodenal (MERRIT, 2003). O controle da secreção clorídrica envolve mecanismos de feedback responsivos a diferentes fatores, como o pH e a composição do alimento. Nesse processo, ocorrem interações complexas entre componentes neurais (nervo vago) e hormonais, envolvendo a gastrina, secretina, colecistocinina, somatostatina, peptídeo liberador de gastrina, histamina, serotonina, acetilcolina, entre outros (JOHNSON, 1971; SANDIN et al., 1999).

A acetilcolina oriunda do nervo vago e a gastrina são os principais ativadores da secreção pelas células parietais, através da bomba de prótons induzida pela ATPase-K-H, que permite o intercambio de $\mathrm{H}^{+} / \mathrm{K}^{+}$na membrana celular, porém, no equino, as células parietais são mais sensíveis à histamina (CAMPBELLTHOMPSON, 1994). A somatostatina e, em menor proporção, o peptídeo relacionado ao gene da calcitonina, inibem a secreção clorídrica ao controlar de maneira parácrina as células produtoras de gastrina e histamina.

O tempo de permanência do alimento no estômago varia entre 2 e 6 horas (WEYENBERG et al., 2006), dependendo diretamente da frequência da ingestão e do tipo de alimento. O estômago raramente fica completamente vazio e a ingestão de alimento estimula a passagem do conteúdo gástrico ao duodeno, promovendo o trânsito normal entre esses compartimentos (GUERRING \& HUNT, 1986). A estrutura anatômica entre o esôfago distal e o cárdia normalmente só permite trânsito no sentido aboral. Assim, sob condições normais, o estômago sempre contém um pouco de gás (COLIN et al., 2005).

$\mathrm{O}$ esvaziamento gástrico em resposta à ingestão de alimento ocorre pelas fases de relaxamento receptivo e de acomodação (LORENZO-FIGUERAS et al., 2002). A fase de relaxamento receptivo do estômago dos equinos envolve mecano-receptores presentes na faringe e/ou esôfago. Já a fase de acomodação depende do controle por feedback de sensores do duodeno, ativados pelo contato do alimento com as mucosas gástricas. Isso justifica a importância do tipo e 
qualidade do alimento oferecido no ajustamento fisiológico, que é dependente da adequação das dietas (MERRIT, 2003).

Mecanismos de defesa da mucosa gástrica

No estômago, a mucosa é a primeira barreira de defesa, sendo submetida a constantes desafios derivados de substâncias e fatores ameaçadores locais e sistêmicos. Portanto, vários são os mecanismos estabelecidos para manter a integridade da mucosa e prevenir lesões. No entanto, as lesões gástricas podem acontecer por fatores agressores que superam os mecanismos de defesa desta ou quando estes estejam alterados (LAINE et al., 2008). Portanto, mecanismos de defesa gástricos locais e neuro-hormonais são de importância na proteção desse órgão.

Barreira muco-bicarbonato-fosfolípides

Essa defesa é constituída por um gel mucoso que protege as superfícies mucosas. Integrada por muco, bicarbonato e fosfolipídios surfactantes, todos secretados pelas células epiteliais da área glandular e estimuladas pela gastrina, secretina, prostaglandinas $\mathrm{E}_{2}\left(\mathrm{PGE}_{2}\right)$ e agentes colinérgicos. $\mathrm{O}$ bicarbonato preserva um microambiente de $\mathrm{pH}$ neutro no epitélio e previne a digestão proteolítica da pepsina à superfície epitelial (ALLEN \& FLEMSTRÖM, 2005).

O muco gástrico, formado por biopolímeros, contém 95\% de água e 5\% de glicoproteínas-mucinas, além de DNA, lipídios, íons, proteínas, células e restos celulares. Todos estes constituintes contribuem para as características físicas e bioquímicas do muco (LAI et al., 2009). Entretanto, alterações nas propriedades reológicas do muco podem afetar suas funções de barreira seletiva e de defesa contra fatores lesivos (SLOMIANY \& SLOMIANY, 1991). Em ambiente ácido do lúmen gástrico, o muco intensifica a viscoelasticidade ao reduzir as cargas negativas dos grupos carboxílicos sobre o ácido siálico nas regiões glicosiladas das estruturas da mucina (LAMONT, 1992).

Vários genes que expressam mucinas, como MUC2, MUC5AC, MUC5B e MUC6, já têm sido descritos, sendo o MUC5AC e MUC6 os mais presentes na superfície gástrica de humanos (HO SB et al., 2004). Entretanto, BULLIMORE et al. (2001) determinaram a semelhança do MUC5AC de humanos com a presente na mucosa do estômago de equinos, havendo produção somente na mucosa glandular. Possivelmente, as mucinas são originadas da mucosa glandular e das vias respiratórias ou das glândulas salivares.

Recentemente, tem-se detectado, na conformação da estrutura do muco, os peptídeos em forma de trevo $\mathrm{pS}_{2}, \mathrm{SP}$, Fator trevo 1, 2 e 3. Os peptídeos conferem estabilidade e maior viscoelasticidade ao muco, catalisando a formação de complexos estáveis de mucinas (THIM et al., 2002), além de prevenir a degradação da pepsina e participar na proteção e reparação da mucosa lesada (BLIKSLAGER, 2004). Quando há processos ulcerativos gástricos e inflamatórios intestinais ocorre aumento na concentração desses peptídeos.

Células epiteliais de superfície

Essa camada celular é parte importante da linha de defesa da mucosa gástrica, já que produz tanto os integrantes do muco como seus estímulos de produção. As células epiteliais encontram-se organizadas pelas junções estreitas e as uniões GAP, oferecendo integralidade e impedindo a difusão retrógrada do ácido e da pepsina. Nos equinos, a proteína conexin 32 das uniões GAP se encontra presente na superfície gástrica glandular como em outras espécies, mas ausente na mucosa pavimentosa (FINK et al., 2006).

A contínua renovação das células progenitoras epiteliais assegura a integralidade e reparação da mucosa, sendo estimado um tempo de substituição epitelial de três a sete dias e de meses para as células das glândulas (LAINE et al., 2008). A renovação celular é coordenada e controlada por fatores de crescimento ativados pela $\mathrm{PGE}_{2}$ e pela gastrina, através da via proteoquinase miogênica ativa (PAI et al., 2002). Além disso, fatores de crescimento também são produzidos pelas glândulas salivares e esofágicas.

As células parietais, além de produzirem ácido clorídrico, também contribuem com os mecanismos de defesa ao secretarem simultaneamente bicarbonato nos capilares que fazem o transporte até as células epiteliais da superfície para formar o gel de muco (LAINE et al., 2008).

Mecanismos de defesa neuro-hormonal

O sistema nervoso central e certos hormônios têm participação conjunta na regulação dos mecanismos de defesa gástrica. Dessa forma, a ação vagal incrementa o muco e o pH intracelular no estômago, o fator liberador corticotrófico (FLC) participa das respostas fisiológicas gastrintestinais ao estresse, inibindo motilidade e apoptose em modelos murinos e humanos (CHATZAKI et al., 2006), assim como também a ativação de receptores opioides centrais potencializam os mecanismos de defesa gástrica.

A arquitetura neurovascular da mucosa gástrica facilita a liberação de oxigênio, nutrientes e remoção de sustâncias tóxicas. A reatividade vascular é intermediada pela liberação de oxido nítrico $(\mathrm{ON})$, prostaglandinas (PGs) e nervos sensoriais aferentes 
por neurotransmissores como peptídeos relacionados com o gene da calcitonina e sustância $\mathrm{P}$ (BRZOZOWSKI et al., 2005; LAINE et al., 2008). Em casos de qualquer ameaça da mucosa, o tônus das arteríolas da submucosa se altera, aumentando a irrigação para remover ou diluir o agente injuriante (STROFF et al., 1995).

A produção contínua de $\mathrm{PGE}_{2}$ e $\mathrm{PGI}_{2}$ sob influência dos receptores EP1-4, estimula ou facilita os mecanismos de defesa, uma vez que inibe a secreção de ácido, estimula a produção de muco, bicarbonato e fosfolipídios, aumenta a irrigação, controla a motilidade gástrica e acelera a restauração epitelial (KOBAYASHI \&ARAKAWA, 1995; HORBUCKLE et al., 2008). Dessa maneira, uma deficiência dessas prostaglandinas na mucosa aumenta a susceptibilidade de lesões ulcerativas, e a administração exógena de PG reduz o risco de úlceras, demonstrando um importante mecanismo na regulação dos fatores defensivos e agressivos na homeostase da mucosa (CRYER, 2001). Porém, o elevado custo e a administração restrita dessas PGs têm incentivado a realização de trabalhos visando à busca de precursores da produção endógena de $\mathrm{PGE}_{2}$

Recentemente, foram identificadas proteínas com funções importantes na mucosa gástrica, tais como: proteínas de choque térmico (HSP) que protegem contra mudanças de temperaturas, estresse oxidativo e agentes citotóxicos (TANAKA et al., 2007). Os peptídeos Catelicidina e ßdefensinas são importantes no sistema imune inato da mucosa contra a colonização bacteriana (YANG et al., 2006). A expressão da proteína Survivin tem se relacionado com funções de modular a apoptose e promover mitoses nas células epiteliais (CHIOU et al., 2005).

Finalmente, tem-se descrito funções protetoras do sulfureto de hidrogênio, já que reduz o fator de necrose tumoral $\alpha$ (TNF- $\alpha$ ), a aderência endotelial de leucócitos e contribui para diminuir as lesões induzidas por anti-inflamatórios não esteróides (AINEs) (FIORUCCI et al., 2006). Outros peptídeos como a gastrina 17 , colecistoquinina, hormônio liberador de tireotropina, bombesina, FLC, FCE, peptídeo YY, neuroquinina $\mathrm{A}$, peptona gástrica e grelina têm sido também evidenciados como fatores com ação protetora e cicatrizante da mucosa gástrica.

Adaptação e citoproteção da mucosa gástrica

A citoproteção adaptativa é a resistência da mucosa adquirida por meio de desafios repetitivos de fatores lesivos. Experimentos em ratos pré-tratados com pequenas quantidades de $\mathrm{PGE}_{2}$ mostraram diminuição da intensidade dos efeitos ocasionados pela infusão intragástrica de álcool 100\% (ROBERT et al., 1983). Os fenômenos de proteção e adaptação da mucosa gástrica, também têm recentemente sido descritos em ratos tratados com AINEs. Em equinos, esses mecanismos de adaptação estão sendo estudados a partir da constatação de que a maior incidência de úlcera gástrica ocorre durante os períodos de aclimatização, comparado com os modelos experimentais de trabalhos que visam esclarecer fatores indutores de gastropatias (GRAAF-ROELFSEMA et al., 2010). Observações clínicas têm mostrado ampla variabilidade de tolerância aos efeitos adversos gastrintestinais dos AINEs não seletivos, o que sugere o desenvolvimento de possíveis mecanismos de autoproteção gástrica

No desenvolvimento da citoproteção adaptativa da mucosa, já são conhecidos mecanismos como a indução de $\mathrm{HSP}, \mathrm{PGE}_{2}, \mathrm{NO}$, secreção de mucina $\mathrm{e}$, mais recente, o índice oxidante-antioxidante e as lipoxinas derivadas da ciclooxigenase-2 (POLAT et al., 2010; BRZOZOWSKI et al., 2011), assim como também a transdução de sinais independentes da síntese de proteínas (TANAKA et al., 2004). Porém, a ativação da tolerabilidade depende do tipo, tempo e da intensidade do agente irritante inicial.

Mecanismos de lesão na mucosa gástrica

Os mecanismos de lesão na mucosa gástrica iniciam na maioria das vezes pelo desequilíbrio entre os fatores protetores intrínsecos (adequada irrigação da mucosa, secreção de muco, prostaglandinas e mecanismos citoprotetores) e os fatores lesivos intrínsecos (produção de ácido clorídrico, acetilcolina, ácidos biliares e pepsina) que alteram os diferentes mecanismos de defesa da mucosa gástrica, resultando em inflamação, erosão ou formação de úlceras (MURRAY \& GRODINSKY, 1989; NAPPER et al., 1989). No entanto, a perpetuação e complicação dessas alterações acontecem pelas peculiaridades anatômicas, fisiológicas e pela combinação com fatores externos.

Diferenças na eficiência dos fatores protetores da mucosa implicam diferenças na apresentação das lesões na superfície gástrica. A causticação na mucosa, resultante do excesso ou falta de tamponamento do ácido clorídrico, AGV e bile altera o transporte ativo de sódio pela mucosa e suas propriedades bioelétricas (ANDREWS et al., 2006), modificando a permeabilidade do epitélio, o que é considerado como a causa primária de lesão na mucosa aglandular sem autoproteção (ARGENZIO, 1999; REESE \& ANDREWS, 2009).

O tipo de manejo dos equinos influencia no $\mathrm{pH}$ do conteúdo gástrico, assim como dietas ricas em 
carboidratos solúveis levam à maior fermentação e produção de $\mathrm{AGV}$, ácido lático, aumento de gastrina e da colonização de bactérias ácido-resistentes, produtoras de metabólitos gastrolesivos que também dificultam a cicatrização (NADEAU et al., 2000; NADEAU et al., 2003; VIDELA\&ANDREWS, 2009). Além da dieta, a frequência e quantidade de alimento e água podem contribuir para o aumento da acidez no estômago (ANDREWS et al., 2006; LUTHERSSON et al., 2009).

As gastroparesias oriundas de distúrbios metabólicos temporários ou crônicos (alterações nos níveis de cálcio, magnésio e glicemia), afecções degenerativas e obstrutivas (câncer, estenoses pilórica) e diminuição no esvaziamento gástrico por efeito farmacológico ( $\alpha$-adrenérgico) geram ambientes propícios para fermentação, que termina levando à isquemia mural, inflamação, neuropatias, morte celular e perda da integridade da mucosa pela distensão gástrica (BLIKSLAGER, 2005).

O esvaziamento gástrico também pode ser comprometido por entidades clínicas que desenvolvem endotoxemia, alterações eletrolíticas e hemodinâmicas (OIKAWA et al., 2007). Processos inflamatórios, obstrutivos e alterações anatômicas intestinais frequentemente alteram a permeabilidade da mucosa gástrica pela combinação de refluxos e hipomotilidade, embora pouco seja reportado à associação entre o local de lesão gastrintestinal e a prevalência de úlceras (RABUFFO et al., 2009). Atividades geradoras de estresse também levam a desequilíbrios neuroendócrinos, caracterizados pelo aumento de gastrina e histamina, sendo estes os principais secretagogos do ácido clorídrico em equinos (CAMPBELL-THOMPSON, 1994). Além disso, o esforço físico muda o ritmo de preenchimento gástrico, o que expõe ao efeito cáustico do ácido na mucosa aglandular (LORENZO-FIGUERAS et al., 2002).

O mecanismo desencadeante de úlceras na área glandular da mucosa é menos entendido, mas pode ser resultante de alterações na defesa desta mucosa por fatores como os AINEs, ao inibir fatores citoprotetores dependentes da produção de $\mathrm{PGE}_{2}$ (MARQUEZ, 2007). As úlceras, nessa área da mucosa, especialmente na região pilórica, se denominam doença ulcerativa glandular primária, embora lesões na mucosa aglandular também são relatadas como decorrentes de toxicoses por AINEs, não pelo efeito primário desses fármacos, mas pelas alterações da motilidade e esvaziamento gástrico (MERRIT, 2003). Úlceras induzidas na área glandular da mucosa gástrica pelo uso de fenilbutazona (FBZ) podem ser acompanhadas de lesões na área aglandular da mucosa, que podem persistir após o uso de promotores de $\mathrm{PGE}_{2}$, como no caso do óleo de milho rico em ácido linoleico. Isso sugere a existência de vias alternativas de resolução.

A toxicidade dos AINEs na mucosa gástrica se apresenta por mecanismos locais diretos e pela diminuição das PGs citoprotetoras da mucosa por inibição sistêmica das COXs (LANAS et al., 2003). As lesões locais derivam da inibição da fosforilação oxidativa mitocondrial em células produtoras de muco, que termina alterando as características hidrofóbicas, pela inibição das quinases e efeitos citotóxicos diretos, como demonstrados in vitro e in vivo (TOMISATO et al., 2004). A maioria dos AINEs são ácidos fracos que, em meio ácido do estômago, são transformados em não ionizados, o que facilita a entrada na célula, onde se ioniza pelo $\mathrm{pH}$ neutro, provocando retenção e liberação de íons de hidrogênio, com potencial para causar alteração da função celular.

Recentemente, tem se reportado o envolvimento dos radicais livres na gênese das lesões independentes da inibição de PGs pelos AINEs na mucosa gástrica (NAITO et al., 1998). Estudos com indometacina demonstraram aumento do peróxido de oxigênio e hidroxilo na superfície gástrica, em resposta à diminuição da atividade da enzima superóxido dismutase (ODABASOGLU et al., 2008). Igualmente, foi descrito desequilíbrio nas concentrações de NO pelo efeito do mesmo anti-inflamatório, bloqueando as propriedades gastroprotetoras (SLOMIANY et al., 1999). A falta de antagonismo na produção de radicais livres pode gerar peroxidação lipídica, em resposta ao estresse oxidativo na mucosa gástrica.

Na medicina equina, o estresse oxidativo já foi relacionado a várias situações clínicas (SOFFLER, 2007). Equinos com restrição alimentar intermitente e tratados com FBZ apresentaram aumento proporcional ao tempo de administração de malonaldeído no conteúdo gástrico e no plasma (ARANZALES \& ALVES, 2011), entretanto, a concentração de NO diminuiu em relação à concentração basal (ARANZALES et al., 2011). Esses resultados sugerem o envolvimento de radicais livres nos efeitos adversos deste antiinflamatório sobre a mucosa gástrica.

Evidências em animais de laboratório sustentam as hipóteses da diminuição de prostanóides e do estresse oxidativo nas alterações gástricas provocadas pelos AINEs em seres humanos, mas em equinos só os efeitos dependentes da inibição das PGs são descritos amplamente. Isso incentiva o desenvolvimento de trabalhos visando a estudar o balanço antioxidante - oxidante na mucosa gástrica desses animais.

Com relação ao mecanismo de diminuição das PGs da mucosa, inicialmente, foi relacionado com 
$\mathrm{COX}_{1}$, mas estudos recentes relataram o envolvimento das duas COXs na síntese de PGs para a manutenção da integridade da mucosa gástrica. De fato, a administração combinada de inibidores seletivos para ambas COXs induz maiores alterações à mucosa, pela diminuição da concentração de $\mathrm{PGE}_{2}$ (WHITTLE, 1981; TANAKA et al., 2001). O uso de AINEs seletivos da $\mathrm{COX}_{1}$ tem mostrado reduzir a irrigação da mucosa gástrica. Adicionalmente, trabalhos em ratos utilizando inibidores da $\mathrm{COX}_{2}$ indicaram aumento na aderência de neutrófilos no endotélio (WALLACE et al., 2000).

A maioria dos AINEs bloqueia a via da COX no metabolismo do ácido araquidônico, mas a via da lipo-oxigenase pode aumentar as concentrações de leucotrienos $\mathrm{B}_{4}$ e $\mathrm{E}_{4}$ com envolvimento em lesões gástricas, como foi demonstrado em trabalhos com fármacos inibidores de $\mathrm{COX}_{1}, \mathrm{COX}_{2}$ e leucotrienos (BIAS et al., 2004). Em seres humanos, os AINEs têm sido relacionados com hemorragias intensas em pacientes com úlceras, devido aos efeitos vasoativos e de agregação plaquetária dos tromboxanos $\mathrm{A}_{2}$. No entanto, esse fato não tem sido descrito em medicina veterinária (TOMLINSON \& BLIKSLAGER, 2003).

\section{CONCLUSÃO}

A sanidade gástrica dos equinos depende do equilíbrio funcional das estruturas constituintes, junto a limitadas mudanças de fatores externos, uma vez que sustâncias lesivas e protetoras endógenas são produzidas simultaneamente. Apesar dos complexos mecanismos de citoproteção e adaptação, o estômago está entre os órgãos mais afetados pela influência da domesticação e pelos atuais sistemas de manejo, criação e modalidades de esportes hípicos. Adicionalmente, alterações gástricas podem repercutir na fisiologia de outros segmentos do trato gastrintestinal, além de alterações de manifestação comportamental que influem no desempenho dos equinos.

\section{AGRADECIMENTOS}

À Coordenação de Aperfeiçoamento de Pessoal de Nível Superior (CAPES), através do Programa Estudantes Convênio de Pós-graduação (PEC-PG), e ao Conselho Nacional de Desenvolvimento Científico e Tecnológico (CNPq), pela concessão das bolsas de doutorado e de pesquisador, respectivamente, e à Universidade de Antioquia pela comissão de estudos

\section{REFERENCIAS}

AL JASSIM, R.; ANDREWS, F. The bacterial community of the horse gastrointestinal tract and its relation to fermentative ácidosis, laminitis, colic, and stomach ulcers. Veterinary
Clinics of North America: Equine Practice, v.25, p.199$215,2009$.

ALLEN, A.; FLEMSTRÖN, G. Gastroduodenal muçus bicarbonate barrier: protection against acid and pepsin. American Journal Physiology Cell Physiology, v.288, p.1-9, 2005. Disponível em: <http://ajpcell.physiology.org/ content/288/1/C1.full.pdf+html>. Acesso em: 27 set. 2012. doi: 10.1152/ajpcell.00102.2004.

ANDREWS, F. Ulcers in the stomach and colon; diagnosis and treatment: a pain in the gut! In: FOCUS MEETING: AMERICAN ASSOCIATION OF EQUINE PRACTITIONERS - AAEP, 2005, Québec. Proceedings... Canada: AAEP, 2005. p.1-7.

ANDREWS, F.M. et al. In vitro effects of hydrochloric acid and various concentrations of acetic, propionic, butyric, or valeric acids on bioelectric properties of equine gastric squamous mucosa. American Journal Veterinary Research, v. 67, n.11, p.1873-1882, 2006. Disponível em: <http:// avmajournals.avma.org/doi/abs/10.2460/ajvr.67.11.1873>. Acesso em: 26 set. 2012. doi: 10.2460/ajvr.67.11.1873.

ARANZALES, J.R.M. et al. Concentración de oxido nítrico y malonaldeído en contenido gástrico de equinos sometidos a los efectos de la fenilbutazona y ayuno. In: ENCUENTRO NACIONAL, 11; INTERNACIONAL DE INVESTIGADORES DE LAS CIENCIAS PECUARIAS (ENICIP), 4., 2011, Medellín Colombia. Revista Colombiana de Ciencias Pecuarias, v.24, n.3, p.424, 2011 .

ARANZALES, J.R.M.; ALVES, GES. Concentraciones de malonaldehido plasmático en equinos con restricción alimenticia y tratados con fenilbutazona. In: ENCUENTRO NACIONAL, 11; INTERNACIONAL DE INVESTIGADORES DE LAS CIENCIAS PECUARIAS (ENICIP), 4., 2011, Medellín Colombia. Revista Colombiana de Ciencias Pecuarias, v.24, n.3, p.424, 2011.

ARGENZIO, R.A. Comparative pathophysiology of nonglandular ulcer disease: a review of experimental studies. Equine Veterinary Journal, v.29, p.19-23, 1999. Disponível em: <http://onlinelibrary.wiley.com/doi/10.1111/j.20423306.1999.tb05163.x/pdf>. Acesso em: 26 set. 2012. doi: 10.1111/j.2042-3306.1999.tb05163.x.

BIAS, P. et al. The gastrointestinal tolerability of the LOX/ COX inhibitor, licofelone, is similar to placebo and superior to naproxeno therapy in healthy volunteers: results from a randomized, controlled trial. American Journal Gastroenterology, v.99, p.611-618, 2004. Disponível em: <http://www.nature.com/ajg/journal/v99/n4/pdf/ ajg2004118a.pdf>. Acesso em: 21 set. 2012. doi: 10.1111/ j.1572-0241.2004.04133.x.

BLIKSLAGER, A. Pathophysiology of mucosal injury and repair. In: REED, S.M. et al. Equine internal medicine. 2.ed. Philadelphia: Saunders, 2004. p.802-815.

BLIKSLAGER, A. et al. Journal of Equine Veterinary Science, v.25, p.98-102, 2005.

BRZOZOWSKI, T. et al. Role of central and peripheral Ghrelin in the mechanism of gastric mucosal defence. Inflammopharmacology, v.13, p.45-62, 2005. Disponível em: <http://www.springerlink.com/content/r6p53q023725 
5318/>. Acesso em: 21 set. 2012. doi: 10.1163/ 156856005774423971 .

BRZOZOWSKI, T. et al. Lipoxins, the novel mediators of gastroprotection and gastric adaptation to ulcerogenic action of aspirin. Current Pharmaceutical Design, v.17, n.16, p.1541-1551, 2011.

BUCHANAN, B.R.; ANDREWS, F.M. Treatment and prevention of equine gastric ulcer syndrome. Veterinary Clinics of North America: Equine Practice, v.19, p.575597, 2003.

BULLIMORE, S.R. et al. Surface mucus in the non-glandular region of the equine stomach. Research in Veterinary Science, v.70, p.149-155, 2001. Disponível em: <http:// www.idealibrary.com>. Acesso em: 21 set. 2012. doi: 10.1053/ rvsc.2001.0455

CAMPBELL-THOMPSON, M.L. Secretagogue-induced aminopyrene uptake in isolated equine parietal cells. American Journal Veterinary Research, v.55, p.132-137, 1994.

CHATZAKI, E. et al. Corticotropin - releasing factor (CRF) receptor type 2 in the human stomach: protective biological role by inhibition of apoptosis. Journal Cell Physiology, v.209, p.905-911, 2006. Disponível em: <http:// onlinelibrary.wiley.com/doi/10.1002/jcp.20792/pdf>. Acesso em: 21 set. 2012 . doi: $10.1002 /$ jcp. 20792 .

CHIOU, S.K. et al. Survivin a novel target for indomethacin induced gastric injury. Gastroenterology, v.128, p.63-73, 2005.

COLIN, F.M. et al. Evaluation of gastrointestinal activity patterns in healthy horses using B mode and Doppler ultrasonography. Canadian Veterinary Journal, v.46, p.134-140, 2005.

CRYER, B. Mucosal defense and repair: Role of prostaglandins in the stomach and duodenum. Gastroenterology Clinical North America, v.30, p.877-894, 2001.

FINK, C. et al. Specific localization of gap junction protein connexin 32 in the gastric mucosa of horses. Histochemical Cell Biology, v.125, p.307-313, 2006

FIORUCCI, S. et al. The emerging roles of hydrogen sulfide in the gastrointestinal tract and liver. Gastroenterology, v.131, p.259-271, 2006.

GRAAF-ROELFSEMA, E.D. et al. The incidence and severity of gastric ulceration does not increase in overtrainedStandardbred horses. Equine Veterinary Journal, v.42, Suppl, p.58-61, 2010. Disponível em: <http://onlinelibrary.wiley.com/doi/ 10.1111/j.2042-3306.2010.00268.x/pdf >. Acesso em: 26 set. 2012. doi: 10.1111/j.2042-3306.2010.00268.x.

GERRING, E.L.; HUNT, J.M. Pathophysiology of equine postoperative ileus: effect of adrenergic blockade, parasympathetic stimulation and metaclopramide in an experimental model. Equine Veterinary Journal, v.18, p.249255, 1986. Disponível em: <http://onlinelibrary.wiley.com/doi/ 10.1111/j.2042-3306.1986.tb03618.x/pdf>. Acesso em: 26 set. 2012. doi: 10.1111/j.2042-3306.1986.tb03618.x.

HO, S.B. et al. The adherent gastric mucous layer is composed of alternating layers of MUC5AC and MUC6 mucin proteins.
Digestive Diseases Sciences, v.49, p.1598-1606, 2004. Disponível em: <http://www.springerlink.com/content/ h48514561448u241/>. Acesso em: 21 set. 2012. doi: 10.1023/ B:DDAS.0000043371.12671.98.

HORBUCKLE, W. et al. Gastrointestinal function. In: KANECO, J. et al. Clinical biochemistry of domestic animal. 6.ed. Davis, California: Elsevier, 2008. Chapt.14, p.417-456.

JOHNSON, LR. Control of gastric secretion: no room for histamine? Gastroenterology, v.61, p.106-118, 1971.

KOBAYASHI, K.; ARAKAWA, T. Arachidonic acid cascade and gastric mucosal injury, protection, and healing: topics of this decade. Journal Clinical Gastroenterology, v.21, p.12$17,1995$.

KÖNIG, H.E. et al. Aparelho digestório. In: KÖNIG, H.E.; LIEBICH, H.G. Anatomia dos animais domésticos. 2.ed. Porto Alegre: Artmed, 2004. p.15-79.

LAI, S.K. et al. Micro- and macrorheology of mucus. Advanced Drugs Delivery Review, v.61, p.86-100, 2009. Duisponível em: 〈www.elsevier.com/locate/addr〉. Acesso em: 24 set. 2012. doi: 10.1016/j.addr.2008.09.012.

LAINE, L. et al. Gastric mucosal defense and cytoprotection: bench to bedside. Gastroenterolgy, v.135, p.41-60, 2008.

LAMONT, J.T. Mucus: the front line of intestinal mucosal defense. Annals of the New York Academicof Science, v.664, p.190-201, 1992

LANAS, A. et al. Clinical implications of COX-1 and/or COX2 inhibition for the distal gastrointestinal tract. Current Pharmaceutical Design, v.9, p.2253-2266, 2003.

LORENZO-FIGUERAS, M. et al. Effects of various diets on gastric tone in the proximal portion of the stomach of horses. American Journal Veterinary Research, v.63, p.12751278, 2002. Disponível em: <http://avmajournals.avma.org/ doi/abs/10.2460/ajvr.2002.63.1275>. Acesso em: 22 set. 2012. doi: $10.2460 /$ ajvr.2002.63.1275.

LUTHERSSON, N. et al. Risk factors associated with equine gastric ulceration syndrome (EGUS) in 201 horses in Denmark. Equine Veterinary Journal, v.41, p.625-630, 2009. Disponivel em: <http://onlinelibrary.wiley.com/doi/10.2746/ 042516409X441929/pdf>. Acesso em: 26 set. 2012. doi: $10.2746 / 042516409 \mathrm{X} 441929$.

MARQUEZ, F.J. Equine gastric ulcer syndrome. Large Animal Veterinary, v.7, n.3, p.1-6, 2007.

MERRIT, A.M. Normal equine gastroduodenal secretion and motility. Equine Veterinary Journal, v. 29, Suppl, p.7-13, 1999. Disponível em: <http://onlinelibrary.wiley.com/doi/ 10.1111/j.2042-3306.1999.tb05161.x/pdf>. Acesso em: 21 set. 2012. doi: 10.1111/j.2042-3306.1999.tb05161.x.

MERRIT, A.M. The equine stomach: a personal perspective (1963-2003). In: ANNUAL CONVENTION OF THE AMERICAN ASSOCIATION OF EQUINE PRACTITIONERS, 49., 2003, New Orleans. Proceedings... Louisiana: AAEP, 2003. p.1-27. 
MURRAY, M.J.; GRODINSKY, C. Regional gastric pH measurement in horses and foals. Equine Veterinary Journal, v.21, p.73-76, 1989. Disponível em: <http://onlinelibrary. wiley.com/doi/10.1111/j.2042-3306.1989.tb05660.x/pdf>. Acesso em: 21 set. 2012. doi: 10.1111/j.20423306.1989.tb05660.x.

MURRAY, M.J. Gastroduodenal ulceration in foals. Equine Veterinary Education, v.11, n.4, p.199-207, 1999. Disponível em: <http://onlinelibrary.wiley.com/doi/10.1111/ j.2042-3292.1999.tb00948.x/pdf>. Acesso em: 25 set. 2012. doi: 10.1111/j.2042-3292.1999.tb00948.x.

MURRAY, M.J. Disorders of the stomach. In: BRADFORD P.S. Large animal internal medicine. 4.ed. St Louis, Missouri, Mosby, 2009. p.695-701.

NADEAU, J.A. et al. Evaluation of diet as a cause of gastric ulcers in horses. American Journal Veterinary Research, v.61, n.7, p.784-790, 2000. Disponível em: <http:// avmajournals.avma.org/doi/abs/10.2460/ajvr.2000.61.784>. Acesso em: 21 set. 2012. doi: 10.2460/ajvr.2000.61.784.

NADEAU, J.A. et al. Effects of hydrochloric, valeric and other volatile fatty acids on pathogenesis of ulcers in the nonglandular portion of the stomach of horses. American Journal Veterinary Research, v.64, p.413-417, 2003. Disponível em: <http://avmajournals.avma.org/doi/abs/10.2460/ajvr.2003. 64.413>. Acesso em: 21 set. 2012. doi: 10.2460/ajvr.2003.64.413.

NAITO, Y. et al. Role of oxygen radical and lipid peroxidation in indomethacin-induced gastric mucosal injury. Digestive Diseases Sciences, v.43, p.30-34, 1998.

NAPPER, G. et al. Gastroduodenal ulceration in foals. Compendium Continue Education Practice Veterinarian, v.11, p.345, 1989.

ODABASOGLU, F. et al. Beneficial effects of vegetable oils (corn, olive and sunflower oils) and $\alpha$ tocopherol on antiinflammatory and gastrointestinal profiles of indomethacin in rats. European Journal of Pharmacology, v.591, p.300306, 2008. Disponível em: <www.elsevier.com/locate/ejphar>. Acesso em: 27 set. 2012. doi: 10.1016/j.ejphar.2008.06.075.

PAI, R. et al. Prostaglandin E transactivates EGF receptor: a novel mechanism for promoting colon cáncer growth and gastrointestinal hipertrophy. Nature Medicine, v.8, p.289293, 2002. Disponível em: <http://www.nature.com/nm/journal/ v8/n3/pdf/nm0302-289.pdf>. Acesso em: 22 set. 2012. doi: $10.1038 / \mathrm{nm} 0302-289$.

POLAT, B. et al. Adaptation of rat gastric tissue against indomethacin toxicity. Chemico-Biological interactions, v.186, p.82-89, 2010. Disponível em: <http://www.deepdyve. com/lp/elsevier/adaptation-of-rat-gastric-tissue-againstindomethacin-toxicity-6K8CxchnLV>. Acesso em: 23 set. 2012. doi: 101016/j.ejphar.2008.06.075.

RABUFFO, T.S. et al. Prevalence of gastric ulcerations in horse whit colic. Journal Equine Veterinary Science, v.29, p.540-546, 2009.

REESE, R.E.; ANDREWS, F.M. Nutrition and dietary management of equine gastric ulcer syndrome. Veterinary Clinics of North America: Equine Practice, v.25, p.79-92, 2009.
ROBERT, A. et al. Cytoprotection by prostaglandins in rats. Prevention of gastric necrosis produced by alcohol, HCL, NaOH, hypertonic $\mathrm{NaCl}$ and thermal injury. Gastroenterology, v.77, p.433-443, 1983.

SANDIN, A. et al. Effects of horse gastrin on gastric acid secretion in horses, dogs and rats. In: SANDIN A. (Ed.). Studies of gastrin and gastric secretion in the horse. Uppsala: Acta Universitatis Agricultura e Sueciae, 1999. p.65-78.

SLOMIANY, B.L.; SLOMIANY, A. Role of mucus in gastric mucosal protection. Journal Physiology Pharmacology, v.42, p.147-161, 1991.

SLOMIANY, B.L. et al. Role oscaspase - 3 and nitric oxide synthase in gastric mucosal injury induced by indomethacin: effect to sucralfato. Journal Physiology Pharmacology, v.50, p.3-16, 1999.

SOFFLER, C. Oxidative stress. Veterinary Clinics of North America: Equine Practice, v.23, p.135-157, 2007.

STROFF, T. et al. Protection by gastrina in the rat stomach involves afferent neurons, calcitonin gene-related peptide, and nitric oxide. Gastroenterology, v.109, p.89-97, 1995.

TANAKA, A. et al. Inhibition of both COX and COX is requerid for development of gastric damage in response $e^{2}$ to nonsteroidal anti-inflammatory drugs. Journal Physiology Paris, v.95, p.2-27, 2001.

TANAKA, K. et al. Adaptive cytoprotection induced by pretreatment with ethanol protects against gastric cell damage by NSAIDs. Digestive Diseases Sciences, v.49, n.2, p.210$217,2004$.

TANAKA, A. et al. Preconditioning stress prevents cold restraint stress induced gastric lesions in rats: roles of COX-1, COX-2 and $\mathrm{PLA}_{2}$. Digestive Diseases Sciences, v.52, p.478-487, 2007.

THIM, L. et al. Effect of trefoil factors on the viscoelastic properties of mucus gels. European Journal Clinical Investigation, v.32, p.519-527, 2002. Disponível em: <http:// onlinelibrary.wiley.com/doi/10.1046/j.1365-2362.2002.01014.x/ pdf $>$. Acesso em: 26 set. 2012. doi: 10.1046/j.13652362.2002.01014.x.

TOMISATO, W. et al. Role of direct cytotoxic effects of NSAID in the induction of gastric lesions. Biochemical Pharmacology, v.67, p.575-585, 2004. Disponível em: <http:/ /www.sciencedirect.com/science/article/pii/ S0006295203007524>. Acesso em: 21 set. 2012. doi: 10.1016/ j.bbr.2011.03.031.

TOMLINSON, J.; BLIKSLAGER, A. Role of nonsteroidal antiinflammatory drugs in gastrointestinal tract injury and repair. Journal American Veterinary Medical Association, v.222, p.946-951, 2003. Disponível em: <http://avmajournals. avma.org/doi/pdf/10.2460/javma.2003.222.946>. Acesso em: 28 set. 2012. doi: 10.2460/javma.2003.222.946.

VIDELA, R.; ANDREWS, F. New perspectives in equine gastric ulcer syndrome. Veterinary Clinics of North America: Equine Practice, v.25, p.283-301, 2009. 
WALLACE, J.L. et al. NSAID-induced gastric damage in rats: requirement for inhibition of both cyclooxygenase 1 and 2 . Gastroenterology, v.119, p.706-714, 2000.

WEYENBERG, S.V. Passage rate of digesta through the equine gastrointestinal tract: a review. Livestock Science, v.99, p.3-12, 2006. Disponível em: <http://ac.els-cdn.com/S0301622605001466/ 1-s2.0-S0301622605001466-main. pdf? tid=b6e91dc0-0b01-11e291f6-00000aab0f02 \&acdnat=1349011456_ce7782b8be005f741b93f 630f4e99b46>. Acesso em: 28 set. 2012. doi: 10.1016/ j.livsci.2005.04.008
WHITTLE, B.J.R. Temporal relationship between cyclooxygenase inhibition, as measured by prostacyclin biosynthesis, and the gastrointestinal damage induced by indomethacin in the rat. Gastroenterology, v.80, p.94-98, 1981.

YANG, Y.H. et al. The cationic host defense peptide rCRAMP promotes gastric ulcer healing in rats. Journal of Pharmacology and Experimental Therapeutics, v.318, p.547-554, 2006. Disponível em: <http://jpet.aspetjournals.org/ content/318/2/547.full.pdf+html>. Acesso em: 27 set. 2012. doi: $10.1124 /$ jpet.106.102467. 